\title{
Counseling Program for Prevention of Cervical Cancer among Women at Assuit, Egypt
}

\author{
Soad Sayed Bayomi \& Neama Mohammed El-Magrabi \\ Assistant Professor of Community Health Nursing, Faculty of Nursing, Assiut University Egypt.
}

\begin{abstract}
Cervical cancer can affect women of all ages, but is most common in women between $30-45$ years of age. Aim of This study was to evaluate the effect of the counseling program on prevention of cervical cancer among women. The study Design: Quiz experimental design. Setting The study was conducted at the Rural Health Unit (RHU) in "El-Masara village Sample : A simple random sample of 160 women who met the required criteria were included. Study tools: An interview questionnaire was used, it consisted of 3 parts: The first part included personal data. The second part assessed women's knowledge about cervical cancer and screening using Pap smear The third part women's attitude about cervical cancer and Pap smear screening. Results: It was found the ages of more than one third of women ranged from 25-30 years. The majority of women had poor knowledge and negative attitude about cervical cancer in the pre- test, which improved significantly after the post-test. Conclusion \& Recommendations: This study concluded that women had limited knowledge about cervical cancer and its prevention. There was a positive correlation between total ' knowledge score and attitude regarding prevention of cervical cancer. The study recommended, raise community awareness and improve their knowledge about the disease and its prevention through counseling program. Also, improve woman's attitude towards screening Pap smear
\end{abstract}

\section{Key word : Cervical Cancer, Screening, Prevention \& Counseling.}

\section{Introduction}

Cervical cancer is a major public health problem, and is considered the second most common cancer in women worldwide $(12 \%)$ following breast cancer; in developing countries and worldwide, with an estimated 529,409 new cases and 274,883 deaths in 2008. About $86 \%$ of the cases occur in developing countries, representing $13 \%$ of female cancers (IARC, 2008). Cervical cancer is a deadly disease in its late stages. Very often, diagnosis of cervical cancer is based on opportunistic screening or after the onset of symptoms. However, out of all the female genital tract cancers, it is the only preventable cancer if detected at its early stages. Population-based screening with Pap smear is an important secondary preventive measure for cervical cancer that leads to a high-cure rate among cervical cancer patients (Foully \& Gomaa, 2015).

Early diagnosis and prompt treatment of cancer and precancerous lesions provides the best possible protection against cervical cancer. Well organized programs to detect and treat precancerous abnormalities at the early stages of cancer prevent up to $80 \%$ of cervical cancer death in developed countries. However, effective cytological screening programs for detecting carcinoma of cervix have been difficult to implement in such country (WHO, 2007).

Cervical cancer is a deadly disease in its late stages. However, out of all the female genital tract cancers, it is the only preventable cancer if detected at its early stages. Population-based screening with Pap smear is an important secondary preventive measure for cervical cancer that leads to a high-cure rate among cervical cancer patients (WHO, 2010).

Counseling is considered very important nursing care role in order to achieve the purpose of cervical cancer prevention and early detection of cases through screening. Providing information on cervical cancer in the community and in health services is vital in raising awareness and reducing illness and preventable death (WHO, 2006). The content of counseling varies but should cover areas like prevention, screening, follow-up, referral, diagnosis, treatment of precancerous conditions and treatment of invasive cancer (Ndikom \& Ofi, 2011). Counseling is a two-way communication between a client and a health worker mainly nurses, to identify and address the client's needs and concerns about cervical cancer screening. It is seen as a necessity in screening and diagnostic and/or treatment services. It includes exchange of important and accurate information between counselor and counselee

(Ndikom \& Ofi, 2011).

Nurses in high income countries play a role in cancer prevention and participate in cervical cancer screening by carrying out Pap smear tests. In countries like Tanzania and India, due to the lack of logistics and scarcity of gynecologists and pathologists, nurses were used effectively in the prevention of cervical cancer, by being enabled to perform Pap smear tests and using visual inspection by acetic acid technique which is less costly and does 
not require high expertise (Turkistanli, 2003 \& Ayres, 2009).

The treatment of patients with cervical cancer has changed significantly over the last few years. Various new therapeutic options are applied according to tumor stage. Patients with disease of limited volume usually undergo radical hysterectomy. For patients with locally advanced disease, extensive radiotherapy, including external pelvic irradiation and brachytherapy, has been the standard treatment for several years. More recently, concurrent chemoradiotherapy has become the treatment of choice for patients with locally advanced cervical cancer and has produced promising results in terms of survival (Urasa \& Darj 2011).

Nurses, being the largest group of health care workers, have an important role in promotion of cervical cancer screening. Early detection is important in the management of cervical cancer, however most of women in developing nations present with advanced disease when little can be done for them (Ayinde et al., 2004).

\section{Significance of the study}

Egypt has 28.37 million women aged 15 years and older who are at risk of developing cervical cancer. Current Egypt summary report indicates that every year 866 women are diagnosed with cervical cancer and $43 \%$ of them die from the disease. Cervical cancer in Egypt ranks as the $10^{\text {th }}$ most frequent cancer among women between 15 and 44 years of age (Bruni et al., 2014). Cervical cancer can affect women of all ages, but is most common in women between $30-45$ years of age. It is rarely found in women under 25 years. The risk of dying from cervical cancer increases as a woman ages (Ferlay et al., 2010).

\section{Aim of this study}

was to evaluate the effect of counseling program on improving woman's knowledge and attitude about prevention of cervical cancer and performing the Pap smear.

Research hypothesis: Women who attend the counseling program about cancer cervix and screening by Pap smear will have better knowledge and attitude than women who did not attend such program.

\section{Subjects \& Methods}

\section{Research design}

A Quazi experimental design was used in carrying out this study .

\section{Setting}

The study was conducted at the Rural Health Unit (RHU) in "El-Masara village". This village is one of the largest villages with the highest density of population in the center of Assiut governorate in Egypt. According to the census of the year 2006, the total population who were working in the winepress were 15470 people, of whom 7477 women. Also, home visit was initiated if the woman could not come to the RHU for the posttest.

\section{Subjects}

All women who attended the RHU at the selected village during the study period were considered the study population. Women usually attend the RHU for baby vaccination according to the schedule of baby vaccination or ante natal care, family planning and follow up at postpartum. Their number was 1600 women.

The researcher randomly selected one tenth of the women who attended during this period. Every tenth woman from each clinic was reached by the researcher and the aim of the study was explained. Women who agreed to participate in the study and met the required criteria were taken till the number reached 160 women.

\section{Inclusion criteria included}

(1)Age between 25-40 years (2) living in the study village for at least 3 months (since most of women leave the village and spend their postpartum period with their family), (3) available to be contacted by phone or home visit; and (4) willing to participate in the study.

\section{Study tools}

An interview questionnaire was developed by the researchers after extensive literature review. The tool consisted of the following parts:

Part (1): Personal data such as: the women's age, occupation and educational level.

Part (2): Women's knowledge about cancer cervix and Pap smear screening, signs and symptoms, causes of cervical cancer, risk factors that increase the risk of cervical cancer, the best possible protection against cervical cancer, diagnosis, treatment and preventing of cervical cancer, etc. (24 questions). The answers were either correct or incorrect. The scoring system was: poor if the woman gets less than $50 \%$, pass $50 \%$ to $70 \%$ and good more than $70 \%$ of the correct answers.

Part (3): Women's' attitude about cervical cancer and screening by Pap smear its included (12 statements). The researcher used a Likert scale. The answers were either agree, not sure or disagree. The woman's attitude was either positive attitude or negative attitude. The positive attitude was affirmed when the woman got more than $70 \%$ and negative when less than $70 \%$. 


\section{Field work}

Administrative approval: The necessary official permission was obtained from the Dean of Faculty of Nursing, Assiut University to proceed with the study. The necessary official permission was obtained from the manager of El-Masara rural health unit; Assiut; Egypt, to conduct the study.

Tool development: The contents of intervention were developed by the researchers based on extensive literature review.

Validity: Three experts in Community Health Nursing and two Gynecologist reviewed the questionnaire and the intervention for content and face validity. Their comments were reviewed and the necessary modifications were done.

Reliability: Reliability of the tools was established using test- retest reliability by administering the test to the same group two times two weeks apart and comparing the answers $(r=0.89)$.

Pilot study: A pilot study was initially carried out on a group of 20 women who came to the RHU for delivery to assess the constructed tool for clarity, feasibility and applicability. The time needed to fill the questionnaire and conduct the counseling was also estimated. The needed modifications of the questions were done, and the approximate time for counseling was calculated.

Ethical consideration: A formal verbal consent was obtained orally from women before being involved in the study since getting a written consent is almost impossible to get from rural women.

. The nature and purpose of the study were explained. The researchers informed the women that there will be no risk or cost for participation, and the participation is voluntary. Also, women were assured about the confidentiality of information and anonymity of subject.

The study started from April 2012 till the end of November 2012. The researchers introduced themselves to the eligible women and briefly explained the aim and nature of the study.

Implementation of the counseling program: The counselling program runs through the following phases:

\section{Assessment phase}

Women were randomly assigned to either the Intervention Group (IG) n=80 or control group (CG). Participants in both groups (160) were asked to fill the 3 parts of the interview questionnaire (pre- test). Women who needed assistant in filling the questionnaire were helped by the researcher. The filling of the interview questionnaire took 15-25 minutes for each participant;

\section{The counseling program}

The CG received the routine care rendered at the RHU, in addition, they were given a pre designed colored booklet with simple explanation about cancer cervix. The IG attended the counseling sessions about cancer cervix and screening by Pap smear.

\section{Content of the counseling session}

The content of the counseling session included discussion about cancer cervix definition, signs and symptoms, complication, treatment and prevention and benefits and attitude towards Pap smear.

The program was implemented the session: The Session: Each woman was interviewed individually. The counseling session took from 40-60 minutes according to the responses and needs of the woman. The aims of the program were explained and discussion of her responses and answers of the questionnaire were done. During this session the researchers used videos, films and posters.

Session: The session were conducted when the mother comes for vaccination or checkups. The IG group were contacted weekly during a period of three months home visit, and/ or if they would visit the clinic for vaccinations, ante natal care, or if any problem aroused. The researchers reassessed woman's knowledge and attitude and stressed on the positive knowledge gained by the woman and feedback was rendered to enforce the positive attitude using role play and videos. Also, they received a pre - designed picture booklet about cervical cancer and screening of Pap smear because the majority of the study sample were illiterates.

Evaluation of the counseling: To evaluate the effectiveness of the counseling program, an interview was conducted with each of the 80 woman to discuss her experience and fill the post- test using the same questionnaire. This session took 60-90 minutes for each woman. Also, estimation of number of women who underwent a Pap smear test was done

\section{Statistical analysis}

Data entry and statistical analysis were done using SPSS 16.0 statistical software package. Data were presented using descriptive statistics in the form of frequencies, mean, standard deviation Statistical significance was considered at $\mathrm{p}$-value $<0.001$. 


\section{Results}

Table (1): Distribution of the studied women according to their socio-demographic characteristics.

\begin{tabular}{|c|c|c|}
\hline Characteristics & No. $(n=160)$ & $\%$ \\
\hline \multicolumn{3}{|l|}{ Age: (years) } \\
\hline $25-$ & 56 & 35.0 \\
\hline $30-$ & 44 & 27.5 \\
\hline $40-$ & 32 & 20.0 \\
\hline$\geq 50$ years & 28 & 17.5 \\
\hline Mean \pm SD (Range) & \multicolumn{2}{|c|}{$36.97 \pm 10.80(20-59)$} \\
\hline \multicolumn{3}{|l|}{ Education } \\
\hline Illiterate & 48 & 30.0 \\
\hline Read \& write & 51 & 31.8 \\
\hline Secondary & 43 & 26.9 \\
\hline University or more & 18 & 11.3 \\
\hline \multicolumn{3}{|l|}{ Occupation } \\
\hline Working & 10 & 6.2 \\
\hline House wives & 150 & 93.8 \\
\hline
\end{tabular}

Table (2): Distribution of the studied women's correct knowledge about cervical cancer in pre, post- tests.

\begin{tabular}{|c|c|c|c|c|c|}
\hline \multirow{2}{*}{ Correct Knowledge } & \multicolumn{2}{|c|}{ Pre-test $(n=160)$} & \multicolumn{2}{|c|}{ Post-test $(n=80)$} & \multirow{2}{*}{ P-value } \\
\hline & No. & $\%$ & No. & $\%$ & \\
\hline \multicolumn{6}{|l|}{ Definition of the cervix } \\
\hline Correct & 10 & 6.25 & 65 & 81.2 & $0.000 *$ \\
\hline \multicolumn{6}{|l|}{ Definition of cervical cancer? } \\
\hline Correct & 4 & 2.5 & 69 & 86.2 & $0.000^{*}$ \\
\hline \multicolumn{6}{|l|}{ Signs and symptoms of Cervical cancer: \# } \\
\hline Foul-smelling vaginal discharge (FSVD) & 6 & 3.8 & 49 & 61.2 & $0.000^{*}$ \\
\hline bleeding & 5 & 3.1 & 65 & 81.2 & $0.000^{*}$ \\
\hline Postcoital bleeding & 5 & 3.1 & 78 & 97.5 & $0.000^{*}$ \\
\hline Dysmenorrhea & 4 & 2.5 & 69 & 86.2 & $0.000^{*}$ \\
\hline Menorrhagia & 6 & 3.8 & 69 & 86.2 & $0.000^{*}$ \\
\hline Don't know & 138 & 86.2 & 0 & 0.0 & $0.000^{*}$ \\
\hline \multicolumn{6}{|l|}{ Complication of cancer cervix \# } \\
\hline Return of cancer after treatment & 8 & 5.0 & 67 & 83.8 & $0.000^{*}$ \\
\hline Spread of cancer to other organs in the body & 20 & 12.5 & 76 & 95.0 & $0.000^{*}$ \\
\hline Bleeding from surgery or inflammation & 18 & 11.2 & 78 & 97.5 & $0.000^{*}$ \\
\hline Don't know & 120 & 62.5 & 0 & 0.0 & $0.000^{*}$ \\
\hline
\end{tabular}


Table (3): Distribution of the studied women's correct knowledge about risk factors, diagnosis, prevention, and treatment of cervical cancer in pre- posttest.

\begin{tabular}{|c|c|c|c|c|c|}
\hline \multirow[b]{2}{*}{ Correct Knowledge } & \multicolumn{2}{|c|}{ Pre-test $(n=160)$} & \multicolumn{2}{|c|}{ Post-test $(n=80)$} & \multirow[b]{2}{*}{ P-value } \\
\hline & No. & $\%$ & No. & $\%$ & \\
\hline \multicolumn{6}{|l|}{ What is the risk factors of cervical cancer\# } \\
\hline -Infection with HPV. & 0 & 0.0 & 44 & 55.0 & $0.000 *$ \\
\hline - Infection with HIV. & 0 & 0.0 & 2 & 2.5 & $0.000 *$ \\
\hline - A multiple pregnancy. & 12 & 7.6 & 69 & 86.2 & $0.000 *$ \\
\hline $\begin{array}{l}\text { The use of birth control pills for long periods (more } \\
\text { than five years). }\end{array}$ & 8 & 5.0 & 69 & 86.2 & $0.000^{*}$ \\
\hline - Sexually transmitted diseases in general. & 4 & 2.4 & 78 & 97.5 & $0.000 *$ \\
\hline - Smoking. & 4 & 2.5 & 79 & 98.8 & $0.000^{*}$ \\
\hline Don't Know & 142 & 88.8 & 0 & 0.0 & \\
\hline \multicolumn{6}{|l|}{ Methods to diagnose cervical cancer. \# } \\
\hline Clinical examination. & 6 & 3.8 & 49 & 61.2 & $0.000 *$ \\
\hline pap smear & 5 & 3.1 & 65 & 81.2 & $0.000^{*}$ \\
\hline Biopsy of the cervix & 6 & 3.8 & 78 & 97.5 & $0.000 *$ \\
\hline Blood chemistry & 4 & 2.5 & 69 & 86.2 & $0.000 *$ \\
\hline X Ray & 4 & 2.5 & 69 & 86.2 & $0.000 *$ \\
\hline Don't know & 142 & 88.8 & 0 & 0.0 & $0.000 *$ \\
\hline \multicolumn{6}{|l|}{ Prevention of Cervical Cancer\# } \\
\hline Periodic pap smear & 10 & 12.5 & 78 & 97.5 & $0.000^{*}$ \\
\hline Cervical cancer vaccine & 3 & 3.8 & 78 & 97.5 & $0.000 *$ \\
\hline It is possible to detect it & 30 & 37.5 & 75 & 93.8 & $0.000 *$ \\
\hline It is preventable & 3 & 3.8 & 59 & 73.8 & $0.000 *$ \\
\hline Early detection & 10 & 12.5 & 32 & 40.0 & $0.000 *$ \\
\hline Screening test & 2 & 2.5 & 69 & 86.2 & $0.000 *$ \\
\hline Don't know & 125 & 78.1 & 0 & 0.0 & $0.000^{*}$ \\
\hline \multicolumn{6}{|l|}{ What are the treatment \# } \\
\hline Chemotherapy & 6 & 3.8 & 69 & 86.2 & $0.000 *$ \\
\hline Radiotherapy & 5 & 3.1 & 65 & 81.2 & $0.000 *$ \\
\hline Surgery & 8 & 5.0 & 69 & 86.2 & $0.000^{*}$ \\
\hline Don't know & 155 & 96.9 & 0 & 0.0 & $0.000 *$ \\
\hline
\end{tabular}

\# More than one answer.

Table (4): Distribution of the studied women's attitude towards cancer cervix in pre, posttests.

\begin{tabular}{|c|c|c|c|c|c|c|c|c|c|c|c|c|c|}
\hline \multirow{3}{*}{ Attitude } & \multicolumn{6}{|c|}{ Pre-test $(n=160)$} & \multicolumn{6}{|c|}{$\operatorname{Post}-\operatorname{test}(n=80)$} & \multirow{3}{*}{$\mathbf{P}$} \\
\hline & \multicolumn{2}{|c|}{ Agree } & \multicolumn{2}{|c|}{ Not sure } & \multicolumn{2}{|c|}{ Disagree } & \multicolumn{2}{|c|}{ Agree } & \multicolumn{2}{|c|}{ Not sure } & \multicolumn{2}{|c|}{ Disagree } & \\
\hline & No. & $\%$ & No. & $\%$ & No. & $\%$ & No. & $\%$ & No. & $\%$ & No. & $\%$ & \\
\hline $\begin{array}{l}\text { I believed that cervical cancer was } \\
\text { curable if detected early, }\end{array}$ & 20 & 12.5 & 2 & 1.3 & 138 & 86.2 & 40 & 50.0 & 3 & 3.8 & 37 & 46.2 & 0.285 \\
\hline $\begin{array}{l}\text { Women can feel they were at risk for } \\
\text { cervical cancer. }\end{array}$ & 22 & 13.8 & 116 & 72.5 & 22 & 13.7 & 73 & 91.3 & 6 & 7.5 & 1 & 1.2 & $0.001^{*}$ \\
\hline $\begin{array}{l}\text { I think that when cervical cancer is detected } \\
\text { early increases the chance for cure }\end{array}$ & 84 & 52.5 & 28 & 17.5 & 48 & 30.0 & 59 & 73.8 & 1 & 1.2 & 20 & 25.0 & $0.001^{*}$ \\
\hline $\begin{array}{l}\text { I feel more comfortable undergoing a } \\
\text { Pap test if the nurse/doctor is a female }\end{array}$ & 36 & 22.5 & 94 & 58.8 & 30 & 18.8 & 43 & 53.8 & 3 & 3.8 & 34 & 42.5 & $0.001^{*}$ \\
\hline $\begin{array}{l}\text { Cervical screening can pick up cell } \\
\text { changes that may go on to become } \\
\text { cervical cancer }\end{array}$ & 64 & 40.0 & 40 & 25.0 & 56 & 35.0 & 35 & 43.8 & 16 & 20.0 & 29 & 36.2 & 0.742 \\
\hline I intend to accept future invitations for & & & & & & & & & & & & & \\
\hline
\end{tabular}




\begin{tabular}{|c|c|c|c|c|c|c|c|c|c|c|c|c|c|}
\hline \multirow{3}{*}{ Attitude } & \multicolumn{6}{|c|}{ Pre-test $(n=160)$} & \multicolumn{6}{|c|}{$\operatorname{Post}-\operatorname{test}(n=80)$} & \multirow{3}{*}{$\mathbf{P}$} \\
\hline & \multicolumn{2}{|c|}{\begin{tabular}{|l|} 
Agree \\
\end{tabular}} & \multicolumn{2}{|c|}{ Not sure } & \multicolumn{2}{|c|}{ Disagree } & \multicolumn{2}{|c|}{ Agree } & \multicolumn{2}{|c|}{ Not sure } & \multicolumn{2}{|c|}{ Disagree } & \\
\hline & No. & $\%$ & No. & $\%$ & No. & $\%$ & No. & $\%$ & No. & $\%$ & No. & $\%$ & \\
\hline cervical screening & 66 & 41.2 & 50 & 31.3 & 44 & 27.5 & 47 & 58.8 & 6 & 7.5 & 27 & 33.8 & $0.001^{*}$ \\
\hline $\begin{array}{l}\text { Cervical screening is effective in } \\
\text { preventing cervical cancer }\end{array}$ & 94 & 58.8 & 8 & 5.0 & 58 & 36.2 & 49 & 61.3 & 1 & 1.2 & 30 & 37.5 & 0.395 \\
\hline $\begin{array}{l}\text { I believe that cervical screening can } \\
\text { pick up signs of ovarian cancer }\end{array}$ & 84 & 52.5 & 28 & 17.5 & 48 & 30.0 & 59 & 73.8 & 1 & 1.2 & 20 & 25.0 & $0.001^{*}$ \\
\hline $\begin{array}{l}\text { Stopping smoking can reduce the risk of } \\
\text { cervical cancer }\end{array}$ & 36 & 22.5 & 94 & 58.7 & 30 & 18.8 & 43 & 53.8 & 3 & 3.8 & 34 & 42.5 & $0.001^{*}$ \\
\hline $\begin{array}{l}\text { Using condoms can reduce the risk of } \\
\text { getting cervical cancer }\end{array}$ & 20 & 12.5 & 2 & 1.3 & 138 & 86.2 & 5 & 6.2 & 0 & 0.0 & 75 & 93.8 & 0.233 \\
\hline $\begin{array}{l}\text { Talking to family/friends about } \\
\text { gynecological symptoms is } \\
\text { embarrassing }\end{array}$ & 124 & 77.5 & 4 & 2.5 & 32 & 20.0 & 63 & 78.8 & 0 & 0.0 & 17 & 21.2 & 0.845 \\
\hline $\begin{array}{l}\text { I'd rather not know if I had cervical } \\
\text { cancer }\end{array}$ & 149 & 93.1 & 10 & 6.3 & 1 & 0.6 & 80 & 100.0 & 0 & 0.0 & 0 & 0.0 & 0.316 \\
\hline
\end{tabular}

P-value1: Comparison between pre-test \& post-test

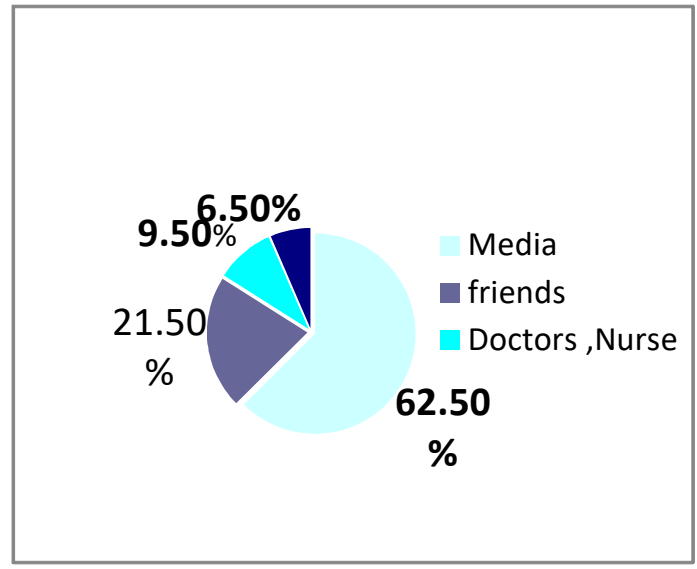

Figure (1): Distribution of the studied women according to their sources of information about cervical cancer $(n=160)$

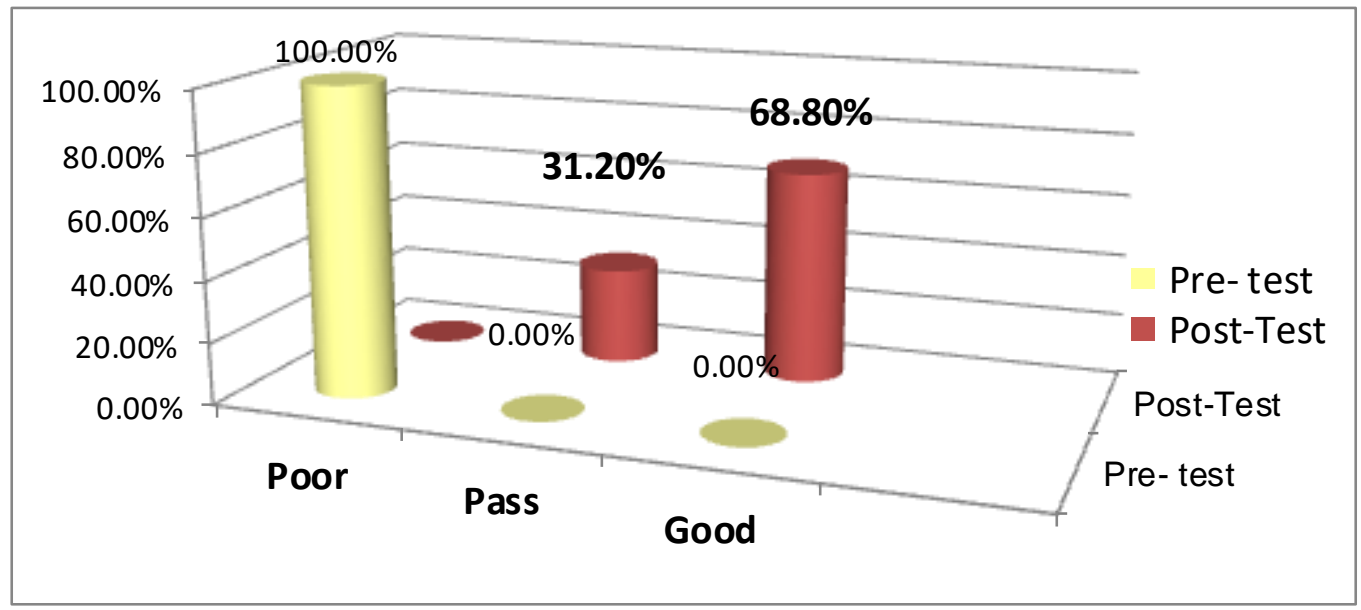

$* \boldsymbol{P}$-value is highly statistically significant difference at $\leq 0.001$ 
Figure (2): Distribution of the total scores of the studied women's correct knowledge about cervical cancer in pre, follow up test (posttest)

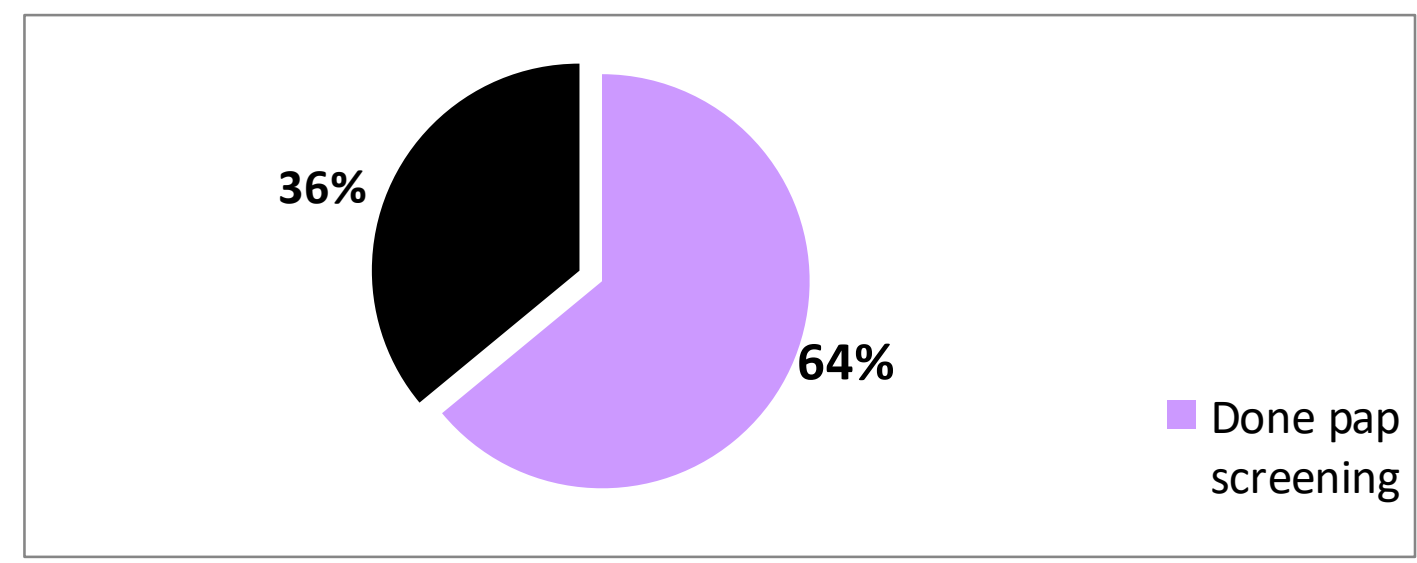

Figure (3): Percentage of women who performed the Pap smear during the period of study

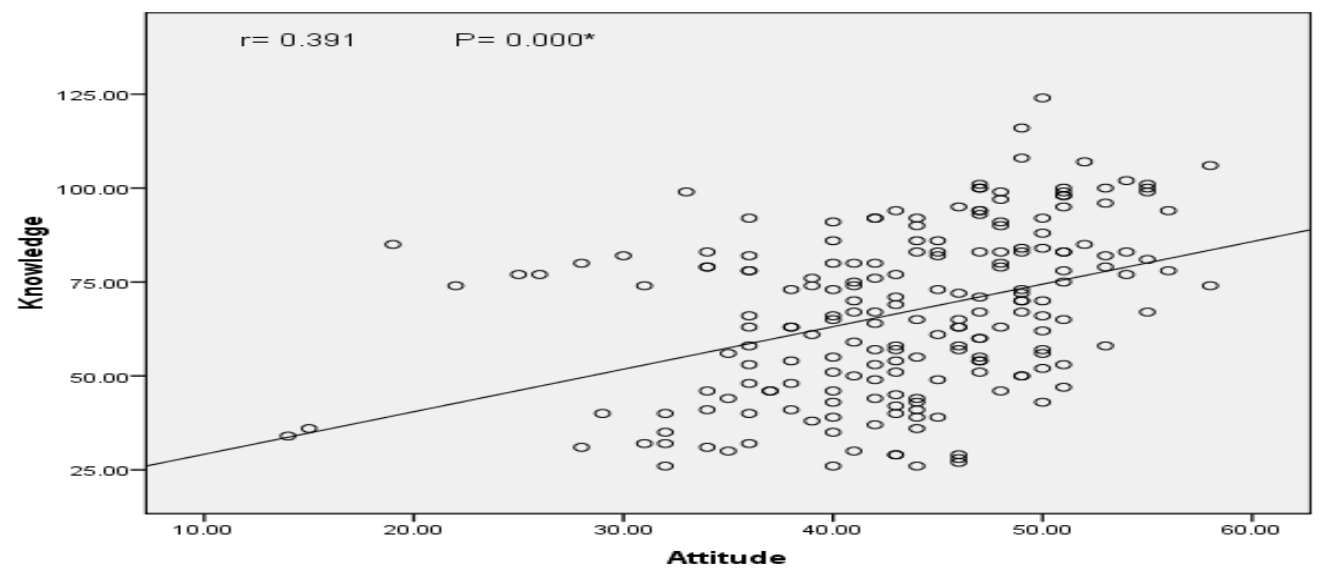

Figure (4). Correlation between the studied women's' total correct knowledge score and total attitude score regarding cervical cancer.

Table (1): showed distribution of the studied mothers according to their socio-demographic characteristics. It was clear that the ages of women $35.0 \%$ ranged from 25-30 years and 27.5\% ranged from $30-<40$ years. Their mean ages were $36.97 \pm 10.80(20-59)$. Regarding to family members, there mean number was $5.69 \pm 1.88(2-10)$. The mean number of rooms was $3.56 \pm 1.27(2-8)$. According to education; the table clarified that $30.0 \%$ and $31.8 \%$ were of them were illiterate, and read and write respectively. Also, 93.8\% were house wives

Table (2): illustrated a highly statistical significant improvement in the studied women's knowledge about cervix and cervical cancer in the post test than that of the pretest .

Table (3): showed a highly statistical significant improvement in the studied women's knowledge about risk factors, diagnosis, prevention, and treatment of cervical cancer in the posttest than that of the pretest $(\mathrm{p} \leq 0.000)$.

Table (4): revealed the comparison between the studied women's attitude towards cancer cervix at the pre- posttest. The table clarified a highly statistical significant improvement in the studied women's attitude towards cervical cancer in the post test than that of the pretest in items as "women can feel they were at risk for cervical cancer, I think that when cervical cancer is detected early, the chance for cure increases, I intend to accept future invitations for cervical screening, I believe that cervical screening can pick up signs of ovarian and stopping smoking can reduce the risk of cervical cancer, also, I feel more comfortable undergoing a Pap test if the nurse/doctor is a female $((\mathrm{p} \leq 001)$. 
Regarding to the studied women's according to their source of information about cervix cancer Figure (1) showed that $62.5 \%$ of the studied women's knew about cancer cervix from the media (T.V, Radio and Internet), $21.5 \%$ from their friend's, while only $9.5 \%$ of them heard from doctor, nurse.

Figure (2): showed the total score of the studied women's' knowledge about cancer cervix in pre and post test. It was clear that all the studied women's $100 \%$ no had one correct knowledge had correct knowledge in the pretest, which improved in the posttest (pass $=31.2 \%)$ and $($ good $=68.8 \%)$. Finally the figure indicated high statistical significant improvement in women's' knowledge in the posttest than that of pretest $(\mathrm{P}=\leq 0.001)$.

Figure (3): illustrated that $64 \%$ of the studied women performed the Pap smear screening during the period of implementation of the counseling program

Figure (4): revealed a high statistical significant positive correlation between total knowledge score and total attitude score of the studied women regarding cervical cancer.

\section{Discussion}

Cervical cancer is a preventable disease and a key aspect of its prevention is early detection of its premalignant form by screening at an early age (Matah \& Sareen, 2012). Counseling is a face-toface, personal and confidential communication aimed at helping a person and his/her family to make informed decisions and then act upon them(Ferlay et al., 2010). WHO, (2006) reported that counseling women will enable them understand the risks and benefits of various screening tests and be able to make informed choices. Counseling therefore is more than advice giving (Ferlay et al., 2010).

The current study showed in table 1 that, more than one third of the studied women's ages ranged from 30-35 years, and almost one third were both illiterate, and read and write respectively.

Most of the studied women included in this study (table 2) were having no correct knowledge about cervical cancer, it was found that the vast majority of them didn't know the definition of cervix, cervical cancer, signs and symptoms. Similar findings was reported by Fouly \& Gomaa (2015) who found that the majority of the study sample had inadequate knowledge on cervical cancer and also similar findings to Tanzania study was reported by Urasa \& Darj, (2011). Also the current study findings were supported by the findings of Mutyaba, Mmiro \& Weiderpass, (2011). This improvement of knowledge could be related to the increase in the level of formal or informal health education about the importance of screening for cancer prevention especially cervical cancer. On the contrary, this result contradicted the results of Hae Won Kim, \& Duck Hee Kim (2014) who mentioned that most of the respondents in there study have knowledge and were aware of cervical cancer and awareness of cervical cancer screening. This could be because of their low level of education and illiteracy. However, there were statistical significant improvement in the knowledge scores at the post test after the counseling program. This difference in the results could be due to cultural differences. As for the knowledge of the studied women regarding to signs and symptoms of servical cancer, the results in table 3 illustrated that their knowledge was statistically improved in the post test than that of the pretest. This results agreed with Jane, (2010) who reported that a little percentage were having fair knowledge regarding signs and symptoms of cervical cancer. On the contrary, this results disagree with Urasa \& Darj (2011) who indicated that three main symptoms of cervical cancer included were vaginal bleeding after the menopause $(66 \%)$, vaginal bleeding during or after sex (64\%), and vaginal discharge that smells unpleasant $(62 \%)$. Only $39 \%$ were able to recognize all three. Just under $30 \%$ were able to recognize two out of three, $16 \%$ recognized one and only $15 \%$ did not recognize any of the three. The most commonly recognized symptom was 'vaginal bleeding between periods' $(73 \%)$. This contradiction could be related to community awareness programs in such country compared to lack of awareness programs about CC in Egypt.

Concerning women's knowledge about risk factors, diagnosis, prevention, and treatment of cervical cancer the current study found that in the pretest, the vast majority of the studied women's didn't know that the risk factors of infection by HPV, HPV, multiple and smoking pregnancy, use a contraceptive pills, sexually transmitted diseases were among the risk factors (Table 2). Their knowledge were improved significantly in the post-test as shown in table 3 which emphasize the importance and success of the counseling program to improve their knowledge. Also, the finding of the present study was in the same line with Ozkilinc, Guler, \& Oztop (2008) who studied the knowledge and screening about cancer cervix. They reported that the majority of their studied sample had inadequate knowledge about transmission of HPV, causes, risks, symptoms, treatment and prevention of cervical cancer, as has been seen in other studies in Uganda, and Nigeria where less than $40 \%$ correctly identified either HPV infection or genetic predisposition. Only two thirds of them identified sexual intercourse as a mode of transmission of HPV. This result is not surprising in a setting where the most commonly known sexually transmitted infections are HIV-AIDS,

Regarding methods for diagnosis of cervical cancer, the current study illustrated that there was statistical 
significant improvement $(\mathrm{p} \geq 0.00)$ at the post test related to identification of methods for the diagnosis of cervical cancer (clinical examination, pap smear, biopsy of cervix, blood chemistry and x-ray).The results is inconsistency with Tacken et al., (2007) who mentioned that there was no significant difference in the level of uptake amongst respondents.

The No correct knowledge about the Pap smear as a screening test for cervical cancer on the pretest was due to the low level of the studied women's education and don't know of knowledge about the purpose or benefits of the test and prevention of cervical cancer which improved in the posttest. Also, this finding was in the same line with Truadpon et al., (2008) who found that some women did not fully understand the purpose of the Pap smear as a method of cervical cancer screening, as $30 \%$ reported that the purpose of the Pap smear test is to screen for STIs. These results suggest that further education about cervical cancer and its prevention will be beneficial to increase awareness.

Also regarding knowledge about diagnosis of cervical cancer in pre test, it was found the majority of the studied women's did not know the clinical examination, pap smea, biopsy of cervix, blood chemestry and x-ray $(12.5 \%, 3.8 \%, 37.5 \%, 3.8 \%, 1$ $2.5 \%)$ respectively. However, their knowledge had improved significantly in the posttest.

Regarding the knowledge of the studied women's about treatment of cervical cancer, in the pre, post, It reveals that the majority of women didn't know the treatment of cervical cancer in the pretest which improved significantly in the follow up test (100.0\%). Concerning the source of information about cervical cancer, more than two thirds of the studied women knew about cervical cancer from the media (T.V, Radio and Internet), while a very low percentage knew about it from doctors/ and or nurses. This result agreed with Goyal, (2013) who documented that the majority of women remembered seeing or hearing of information about cervical cancer in television, newspapers, women's magazines, and radio. Also, in the same line Jane (2010) reported that the source of information was through mass media, print media and internet. Similar patterns of awareness were recorded in a Nigerian study by Hislop et al., (2004) in Benin and Ibadan. In a survey of 195 health workers in the Benin study, more than $65 \%$ of the respondents were having knowledge about cervical cancer from the media. Regarding to the total score of attitude, table 4 showed the distribution of women's' attitude toward cancer cervix improved significantly at the post test, than that of the pretest where $\mathrm{P} \geq 0.001$ in attitude items as "women are at risk for cervical cancer, I think that early detection of cervical cancer increases the chance for cure, I intend to accept future invitations for cervical screening, I believe that cervical screening can pick up signs of ovarian cancer and quitting smoking can reduce the risk of cervical cancer". In the same line, Lyons (2010) reported that $96 \%$ of participant believed that early diagnosis was important in maximizing the chances of cure and their attitudes to screening were positive, $74 \%$ believed cancer screening to be effective in preventing cancer. Only $45 \%$ were able to recognize all warning signs. $69 \%$ knew about the vaccination program and that the vaccine is offered between 12 and 18 years. Likewise, three quarters of women agreed that screening is effective in preventing cervical cancer. $51 \%$ agreed that using condoms could reduce the risk of cervical cancer. Fewer than $10 \%$ of women were able to recall smoking as a risk factor. Ozkilinc, (2008) in America mentioned that $70 \%$ of adults 18years and older have never heard of $\mathrm{HPV}$, the causative agent for cervical cancer. In the present study, the researchers found that $41.9 \%$ respondents heard about the Pap smear test and 9.8\% had the test done which are higher than that in the study conducted in Nigeria where among those who knew about the Pap smear test, $61.1 \%$ respondents did not have the test mainly because of personal factors such as fear of the procedure, cultural or religious reasons. Also, Goyal et al., (2013) found that $70 \%$ of participants believed that cancer cervix is preventable, detectable at an early stage and curable if detected early. Similar findings were reported in the Kolkota study by Byrd, Petterson, Chavez, Heckert (2004) where most of the women did not appreciate the importance of preventive health check up in the absence of symptoms. Among African American and Hispanic women, Kelly \& Kimberlee, (2007) reported that absence of symptoms and perception of vulnerability determined Pap smear testing. Not knowing where to go was also found to be a significant barrier among Hispanic women. This improvement in the studied women's attitude correlates to the success of the counseling program that raises their awareness about cervical cancer risk factors, feasibility and affordability of the diagnostic procedures and effectiveness of the early diagnosis in preventing the needless death due to cervical cancer. Several factors may affect a woman's ability and desire to participate in cervical cancer prevention programs for not getting the screening test done in spite of a desire to do so were mainly: no awareness, no disease or symptoms, do not know where to go, no one is doing it and never thought of it. In this study, figure 3 showed that almost two thirds of the studied women voluntarily - during the 3 months of the study- performed the screening with Pap smear. Thus, knowledge factors accounted for positive 
healthy behavior and change in attitude is evident from figure 4 as incorrect of knowledge about the disease, absence of the concept of preventive behavior appear to be important factors that lead to success of the counseling program. Therefore, in the context of implementing a successful program it is essential to identify the reasons that prevent a woman from using the services (Allison, et al., 2005)

\section{Conclusions}

According to study finding and research hypothesis

- This study concluded that; the studied women had incorrect knowledge about cervical cancer and even less about -screening, treatment and prevention.

- The counseling program was successful in improving the studied women's knowledge and attitude towards cervical cancer and performing a screening test for prevention, early detection and treatment.

- There was a positive correlation between total score of women's' knowledge and total score of women's attitude regarding prevention cervical cancer.

- Almost one third of the studied women voluntarily performed the screening by Pap smear during the study period.

\section{Recommendations}

- Health education for women who attending in maternal and child health and rural health units about cervical cancer risk factors, signs and symptoms, prevention by vaccination of young girls among other activities, early detection and prompt treatment.

- More research is needed in different settings and larger sample size to maximize the benefits of early detection of cervical cancer cases.

\section{Reference}

1. Urasa M., \& Darj E., (2011): Knowledge of cervical cancer and screening practices of nurses at a regional hospital in Tanzania. AFR Health SCiMar11(1):48-75.

2. Ayres C., (2009): Said another way nurses' role in cancer control. Nurs Forum; 44(1):6467. [PubMed].

3. Allison B., Amie B., Patricia C., Jennifer W., Janet B., \& Ilana D., (2003): Factors affecting preventive services in low resources settings. Salud Publica de Mexico; 45 : S408-15.

4. Ayinde O., Omigbodun A., (2003): Knowledge, attitude and practices related to prevention of cancer of the cervix among female health workers in Ibadan. J Obstet Gynaecol; 23(1):59-62.

5. Bruni L., Barrionuevo-Rosas L., Serrano B., Brotons M., Albero G., Cosano R., Muñoz J., Bosch F., de Sanjosé S., Castellsagué X., (2014): ICO Information Centre on HPV and Cancer (HPV Information Centre). Human Papillomavirus and Related Diseases in Egypt. Summary Report August [Data Accessed].

6. Byrd T., Petterson S., Chavez R., \& Heckert A., (2014): Cervical cancer screening beliefs among young Hispanic women. Prev Med; 38 : 192-7.

7. Ferlay J., Shin H., Bray F., Forman D., Mathers C., \& Parkin D., (2010): Cancer Incidence and Mortality worldwide: IARC Cancer Base No. 10. GLOBOCAN, 2008. Lyon . France: International Agency for Research on Cancer; Available at: http:// globocan.iarc.fr.

8. Fouly1 \& Gomaa, (2015): Exploring of Cervical Cancer's Knowledge among Female Nursing Students Based on Junior and Senior grades' information IOSR Journal of Nursing and Health Science (IOSR-JNHS) e-ISSN: 2320-1959.p- ISSN: 2320-1940 Volume 4, Issue 2 Ver. II (Mar.-Apr. 2015), PP 08-13 www.iosrjournals.org

9. Goyal, Gunvant Vaishnav, Anjani Shrivastava, Ragini Verma, \& Anjali Modi (2012): Knowledge, Attitude \& Practices About Cervical Cancer And Screening Among Nursing Staff In A Teaching Hospital International Journal of Medical Science and Public Health Vol 2 | Issue 2

10. Hae Won Kim, I., \& Duck Hee Kim, (2014): Awareness of cervical cancer prevention among mothers of adolescent daughters in Korea: qualitative research Downloaded from http://bmjopen.bmj.com/ on - Published by group.bmj.com

11. Hislop T., Teh C., Lai A., Ralston J., Shu J., \& Taylor V., (2004): Pap screening and knowledge of risk factors for cervical cancer in Chinese women in British Columbia, Canada. Ethn Health; 9(3):267-81. [Crossref]

12. Hoque, E., \& Hoque M., (2009): Knowledge of and attitude towards cervical cancer among female university students in South Africa South Afr J Epidemiol Infect;24(1):21-24 .

13. International Agency for Research on Cancer (IARC), Globocan (2008): in WHO/ICO Information Centre on HPV and Cervical Cancer (HPV Information Centre). Human Papillomavirus and Related Cancers in Nigeria. 
Summary Report 2010. Accessed 2nd August, at www.who.int/hpvcentre

14. Jane L., (2010): Department of Health The Eve Appeal is working to raise awareness of the signs and symptoms of cervical cancer. To find out more please visit www.eveappeal.org.uk

15. Kelly A., \& Kimberlee G., (2007): Factors influencing cancer screening 18. practices of underserved women. J Am Acad Nurse Pract ; 19 : 591-601.

16. Lyon, (2010): Cancer Incidence \& Mortality worldwide: IARC Cancer Base No. 10. Globocan, 2009. . France: International Agency for Research on Cancer; Available at: http:// globocan.iarc.fr..

17. Matah M., \& Sareen S., (2012): Detection of HPV by PCR-A novel step in the prevention of Cancer Cervix. J Obstet Gynaecol India;62 (2):188-191.

18. Mmiro F., \& Weiderpass E., (2006): Knowledge, attitudes and practices on cervical cancer screening among the medical workers of Mulago Hospital, Uganda. BMC Med Educ. ;6:13.[PMC free article] [PubMed].

19. Mutyaba T., Mmiro F., \& Weiderpass E., (2011): Knowledge, attitudes and practices on cervical cancer screening among the medical workers of Mulago Hospital,

20. Ndikom C., \& Ofi B., (2011): Pre-screening counseling in cervical cancer prevention Implications for nursing: International Journal of Nursing and Midwifery Vol. 3(10), pp. 158-164, 3 October, 2011. Available online at http://www.academicjournals.org/IJNM ISSN 2141-2499 @2011 Academic Journals Full Length Research Papers ,Department of Nursing, College of Medicine, University of Ibadan, Oyo state, Nigeria. Accepted 8 August,.

21. Ozkilinc G., Guler A., \& Oztop I., (2008):. Awareness of breast and cervical cancer risk factors and screening behaviours among nurses in rural region of Turkey. Eur $\mathrm{J}$ Cancer Care (Engl) ;17(3):278-284. [PubMed].

22. Tacken M., Braspenning J., Hermens R., Spreeuwenberg P., Van Den Hoogen H., \& De Bakker D., (2007): Uptake of cervical cancer screening in the Netherlands is mainly influenced by women's beliefs about the screening and by the inviting organization. Euro $\mathrm{J} \mathrm{Pu}$.

23. Truadpon P., Inpa C., Sangpetngam B., Mekjarasnapa M., \& Apirakarn M., (2008): Knowledge, Attitudes and Practices vis-a-vis Cervical Cancer among Registered Nurses at the Faculty of Medicine, Khon Kaen University, Thailand. Asian Pac J Cancer Prev;9(1):15-18.
24. Turkistanli E., Sogukpinar N., Saydam B., \& Aydemir (2003): Cervical cancer prevention and early detection - the role of nurses and midwives. Asian Pac J Cancer Prev.;4(1):1521.

25. Weiderpass E., (2011): Knowledge, attitudes and practices on cervical cancer screening among the medical workers of Mulago Hospital, Uganda. BMC Med Educ. ;6:13.

26. WHO, (2010): ICO information Centre on HPV and Cervical Cancer. India: Human Papillomavirus and Related Cancers, Fact Sheet. Available at: www.who.int/hpvcentre .

27. World Health Organization, (2007): Cervical cancer, human Papillomavirus (HPV) and HPV vaccine: key points for policymakers and health professionals. World Health Organization. Available rom: www.who.int/reproductivehealth/publications/ca ncers/RHR_08_14/en/index.html 